\title{
UMA ANÁLISE DO FILME DESCOBRIMENTO DO BRASIL
}

\author{
Eduardo Victorio Morettin \\ Professor da UNIP/SP
}

RESUMO: Este escrito analisa o filme Descobrimento do Brasil, de Humberto Mauro. O filme pretendeu fidelidade realista ao acontecimento apresentado, citando documentos de época. Estratégias narrativas demonstram conexões entre a obra de Mauro e o universo político brasileiro dos anos 30

PALAVRAS-CHAVE: Cinema brasileiro - Humberto Mauro - Cultura na era Vargas - Brasil colonial.

ABSTRACT: This paper discusses Humberto Mauro's movie The discovery of Brazil. The movie claimed realist fidelity on exhibited event refering epoch documents. Narrative strategies prove links between Mauro's work and brazilian political universe of 30 s.

KEYWORDS: Brazilian cinema - Humberto Mauro - Vargas years culture - Colonial Brazil.

Descobrimento do Brasil (1937), de Humberto Mauro, faz parte de um amplo cenário cultural que buscava legitimar simbolicamente o regime de Getúlio Vargas, visto como responsável pela consolidação do Estado Nacional. Apesar de não ser pura e simplesmente uma "peça de propaganda", a obra de Mauro, em função do próprio tema, encaixava-se perfeitamente na idéia de formação de um corpo coeso em torno de objetivos comuns e comandado por um líder que se punha acima das possíveis divergências sociais. Suas imagens, como a da recepção dos índios pelos portugueses na embarcação de Pedro Álvares Cabral, constróem uma representação harmônica de nosso passado, afinada com o período. No entanto, como já foi apontado, não podemos reduzir o trabalho do diretor mineiro a um puro reflexo de seu momento. 
Descobrimento... foi produzido pelo Instituto de Cacau da Bahia, inserindo-se num projeto mais amplo de discussão acerca das possibilidades do uso do cinema para fins educativos (MORETTIN). De acordo com esse projeto, era importante validar "cientificamente" o discurso cinematográfico, adotando-se estratégias de autenticação com o objetivo de diferenciar o filme educativo dos melodramas da época, nos quais não existia a preocupação com a chamada verdade histórica. Isso pode ser percebido pelos créditos iniciais de Descobrimento..., onde, além da equipe técnica, são apontados os responsáveis pela orientação histórica do filme, a saber, Afonso de Taunay, diretor do Museu Paulista, e Edgar Roquette-Pinto, dois intelectuais reconhecidos em seu período. Somos informados também da participação do renomado Heitor Villa-Lobos, compositor da música utilizada pelo filme, e de Mário de Queiroz, coreógrafo das danças indígenas.

Além dos dados contidos na apresentação do filme, a narrativa recorre a diversas estratégias de legitimação, dispostas no interior de seu próprio discurso. Um dos principais elementos abonadores da fidelidade histórica de Descobrimento... foi o uso da Carta de Pero Vaz de Caminha. A idéia dos realizadores do filme era a de colocar o documento em primeiro plano, como se a fonte e, conseqüentemente, a História falassem por si. A Carta foi empregada como base de elaboração de diversas seqüências. Apesar de feito em pleno cinema sonoro, a obra recorreu aos letreiros, que, em sua maior parte, são transcrições literais do relato de Caminha. Estas transcrições são acompanhadas das devidas aspas, indicando a preocupação com a referência às fontes, procedimento do fazer histórico transposto para a narrativa cinematográfica.

A recorrência ao documento completa-se com a tentativa de conduzir a narrativa pelo olhar do escrivão, como se a identidade entre o seu ponto de vista e aquilo que a câmera nos mostra fosse suficiente para atestar a autenticidade do relato fílmico. Mesmo nas cenas onde o seu olhar não conduz o ponto de vista da seqüência, a simples presença de Caminha representaria o elo de ligação entre o que está descrito no documento textual e o filme, firmando a autoridade da tradução da fonte histórica em imagens.

Nesse sentido, cabe ressaltar o momento em que Caminha é inserido na história. De acordo com os dados fornecidos pela narrativa, e conforme a cronologia da própria Carta, encontramo-nos entre os dias 14 e 22 de março. No interior do navio, vemos o escrivão abrir um maço de folhas, onde se lê na capa: "Cuaderno de Pero Vaz de Caminha/Escrivam d'El Rei”. É importante destacar que estas páginas estão em branco, indicando que o trabalho de registro das observações está por ser feito. Isso significa que as imagens posteriores terão, direta ou indiretamente, relação com o preenchimento daquele diário.

Estabelece-se aí um paralelo entre dois campos: um, mais amplo, vinculado a tudo o que a narrativa nos mostra; outro, mais restrito, correspondente a Caminha e a sua história. Dado que a instância do oficial é aquela que confere autenticidade ao discurso, a narrativa precisa nos fazer crer que, a partir da apresentação do caderno, tudo aquilo que veremos será fruto da coleta de informações a ser registrada ao longo da viagem. Para tanto, bastam o olhar e a presença de Caminha para conferir veracidade à descrição. É por isso que voltamos ao caderno apenas no final, depois da encenação da Primeira Missa, quando o escrivão lê os trechos finais de seu relato a Cabral e a frei Henrique, entre outros, submetendo-o à apreciação de seus superiores.

A maneira pela qual essas questões se apresentam reflete uma opção da narrativa, além de marcar a especificidade do próprio cinema. Uma primeira questão diz respeito à cronologia, tão prezada por historiadores como Taunay. Certamente, era de seu conhecimento, por intermédio de Capistrano de Abreu, que a carta fora escrita após a chegada ao Brasil, muito provavelmente a partir da noite de 26 de abril (CAPISTRANO DE ABREU), e não antes. Descobrimento..., confor- 
me indicado acima, antecipa o início do trabalho de registro a fim de que possamos acompanhar o relato com a testemunha daquele momento histórico. Dentro do campo de competências desses intelectuais, há aí um curioso sacrifício da chamada verdade histórica em detrimento da composição fílmica. Em relação à primeira parte da obra, obedecer à discussão historiográfica traria um problema de difícil resolução para o narrador: como conciliar o caráter testemunhal dos fatos observados e o apego à objetividade científica sem que as cenas fossem permeadas pela presença/ olhar de Caminha?

A solução dada pela narrativa parece resolver o problema, e essa resolução aponta para a singularidade do cinema. O meio adotado para se contar a história do descobrimento é diverso dos outros suportes até então utilizados, quer a história, quer as artes plásticas, solicitando arranjos diferentes dos conhecidos até então. Assim, cabe ressaltar mais uma vez, que nem tudo corresponde ao olhar de Caminha ou é transposição de sua carta, bastando para isso indicar, por exemplo, todas as imagens que se encontram antes da apresentação do escrivão e depois da partida da esquadra de Cabral rumo às Índias.

Dentre essas imagens, destaco uma sequiência anterior à da apresentação do oficial. No interior de um navio, à noite, percorremos, entre outros ambientes, o alojamento dos marinheiros. Preside a sequiência um tom, que se não é sombrio ou melancólico, certamente está distante da euforia enunciada pelos planos antecedentes. A música de Villa-Lobos é empregada com o intuito de corroborar esse sentido. Um dado importante reside no fato de que desde o início da seqüência, somos levados a acreditar que a música é um elemento externo à ação das personagens apresentadas. No entanto, a camêra, ao deslo- car-se pelo ambiente, mostra-nos um marinheiro tocando o instrumento que produz a música por nós ouvida. Este sutil movimento de internalização de um dado a priori externo confere à música de Villa-Lobos um tônus de autenticidade, pois ela é representada como se fosse de época.

A trilha sonora da versão em vídeo, lançada em 1997 pela Funarte, foi completamente adulterada. No lugar da trilha original, os "restauradores" usaram a gravação de 1993 de Descobrimento..., feita por Roberto Duarte, com o Coro e Orquestra da Rádio de Bratislava. Entre outras perdas - como sabemos, cada regente tem a sua visão sobre a obra que conduz -, destaco a modificação feita nesta sequiência, na qual, ao invés do instrumento desenvolvendo o seu tema em solo, ouvimos a música orquestrada. O sentido original, conforme apontado acima, perde-se completamente.

Aquela pequena seqüência nos coloca algumas indagações. Qual seria o estatuto do narrador nesses momentos iniciais? Se os olhos de Caminha conferem ao discurso o tom de testemunho verídico, quem nos apresenta as primeiras cenas? Se a Carta inspira a verdade histórica sobre a qual se assenta o discurso fílmico, quais seriam as bases que garantiriam o grau de cientificidade aos primeiros momentos da obra?

Essas questões podem ser aplicadas para outras seqüências também. Claro está que há uma narração que engloba o ponto de vista de Caminha, superando-a na construção de um olhar sobre o novo mundo. Identificála a partir do exame do específico fílmico é uma das tarefas que ainda nos cabe neste momento, a fim de que possamos analisar a adequação ou não do filme aos projetos ideológicos que se encontram em sua origem.

Trata-se de um convite à reflexão em meio a tantos festejos, quer sobre os 500 anos, quer sobre o próprio Humberto Mauro. 


\section{Bibliografia}

CAPISTRANO DE ABREU, João. Descobrimento do Brasil. Sem local, Sociedade Capistrano de Abreu, 1929.

MORETTIN, Eduardo. A representação da história no cinema brasileiro (1907/ 1949), in Anais do Museu Paulista (História e Cultura Material). São Paulo, Nova série. v. 5: p. 249/ 271, janeiro/dezembro de 1997. 